\title{
Neutron activation of holmium poly(L-lactic acid) microspheres for hepatic arterial radioembolization: a validation study
}

\author{
M. A. D. Vente - J. F. W. Nijsen • R. de Roos • M. J. van Steenbergen • C. N. J. Kaaijk • \\ M. J. J. Koster-Ammerlaan • P. F. A. de Leege • W. E. Hennink • A. D. van het Schip • \\ G. C. Krijger
}

Published online: 25 February 2009

(C) The Author(s) 2009. This article is published with open access at Springerlink.com

\begin{abstract}
Poly(L-lactic acid) microspheres loaded with holmium-166 acetylacetonate $\left({ }^{166}\right.$ Ho-PLLA-MS) are a novel microdevice for intra-arterial radioembolization in patients with unresectable liver malignancies. The neutron activation in a nuclear reactor, in particular the gamma heating, damages the ${ }^{166}$ Ho-PLLA-MS. The degree of damage is dependent on the irradiation characteristics and irradiation time in a particular reactor facility. The aim of this study was to standardize and objectively validate the activation procedure in a particular reactor. The methods included light- and scanning electron microscopy (SEM), particle size analysis, differential scanning calorimetry, viscometry, thermal neutron flux measurements and energy deposition calculations. Seven hours-neutron irradiation
\end{abstract}

M. A. D. Vente $(\bowtie) \cdot J$. F. W. Nijsen • R. de Roos •

A. D. van het Schip

Department of Radiology and Nuclear Medicine,

University Medical Center Utrecht,

P.O. Box 85500, 3508 GA Utrecht, The Netherlands

e-mail: m.vente@umcutrecht.nl

M. J. van Steenbergen · W. E. Hennink

Department of Pharmaceutics,

Utrecht Institute for Pharmaceutical Sciences, Utrecht University,

Utrecht, The Netherlands

C. N. J. Kaaijk • M. J. J. Koster-Ammerlaan • P. F. A. de Leege

Reactor Institute Delft, Faculty of Applied Sciences,

Delft University of Technology,

Delft, The Netherlands

G. C. Krijger

Department of Radiation, Radionuclides and Reactors,

Faculty of Applied Sciences, Delft University of Technology,

Delft, The Netherlands results in sufficient specific activity of the ${ }^{166}$ Ho-PLLAMS while structural integrity is preserved. Neutron flux measurements and energy deposition calculations are required in the screening of other nuclear reactors. For the evaluation of microsphere quality, light microscopy, SEM and particle size analysis are appropriate techniques.

Keywords Holmium - Microspheres - Neutron irradiation . PLLA $\cdot$ Liver Tumor

\section{Introduction}

The global incidence of hepatocellular carcinoma (HCC), the most common type of primary liver cancer, is high ( $>600,000$ new cases per year) and still increasing (Gomaa et al. 2008; Parkin et al. 2005). The only potentially curative treatment option in HCC is surgical resection. Unfortunately, most patients are presented with unresectable disease, and due to the lack of effective treatment alternatives, HCC is the 3rd cause of cancer related death (Parkin et al. 2005). The liver is also a very common organ for other cancers to spread to. This is especially the case for primary cancers of the gastrointestinal tract. Metastasis confined to the liver very often occurs in colorectal cancer, of which the global incidence is very high as well $(\sim 1,000,000$ new cases per year), particularly in the Western World. Colorectal cancer ranks as the 3rd most commonly diagnosed cancer type. The primary potentially curative treatment for colorectal liver metastases is surgical resection as well, yet only a minority of patients is eligible. The overall prognosis of colorectal cancer is rather good 
but, due to the high incidence and the reality that metastases in the liver are often unresectable, colorectal cancer is the 4th cause of cancer related death (Parkin et al. 2005). Therefore, the need exists for novel treatment options for patients with unresectable liver malignancies.

One emerging treatment option for patients with unresectable liver tumors is intra-arterial microbrachytherapy via radioactive microspheres, loaded with the high-energy beta-emitting radioisotope yttrium- $90\left({ }^{90} \mathrm{Y}: E_{\beta \max }=2.28 \mathrm{MeV}\right.$, $I_{\beta}=99.9 \% ; T_{1 / 2}=64.1 \mathrm{~h}$ ), instilled into the hepatic artery (Gulec and Fong 2007; Vente et al. 2007). The ${ }^{90} \mathrm{Y}$ microspheres are deposited into the liver tumors in much higher concentrations than into the non-tumorous liver as a consequence of the difference in blood supply between the normal liver and liver tumors. The normal liver is supplied by both the hepatic artery and (mainly) the portal vein, whereas liver tumors derive their blood uniquely from the hepatic artery (Bierman et al. 1951).

Apart from these ${ }^{90} \mathrm{Y}$ microspheres, holmium-166 loaded poly(L-lactic acid) microspheres $\left({ }^{166}\right.$ Ho-PLLA-MS) are being developed for clinical application (Zielhuis et al. 2006a; Nijsen et al. 2001). Whereas ${ }^{90} \mathrm{Y}$ is a pure beta emitter, ${ }^{166} \mathrm{Ho}$ is a combined beta-gamma emitter $\left({ }^{166} \mathrm{Ho}\right.$ : $E_{\beta \max }=1.77$ and $1.85 \mathrm{MeV}, I_{\beta}=48.7 \%$ and $50.0 \%$, respectively; $\left.E \gamma=81 \mathrm{keV}, I \gamma=6.7 \% ; T_{1 / 2}=26.8 \mathrm{~h}\right)$ and highly paramagnetic as well. It therefore offers medical imaging possibilities, through both single photon emission computed tomography (SPECT) and magnetic resonance imaging (MRI). Quantitative analysis of the SPECT scans and the MRI scans has been demonstrated feasible (De Wit et al. 2006; Nijsen et al. 2004; Seppenwoolde et al. 2004). ${ }^{165}$ Ho-PLLA-MS are prepared through a straight-forward solvent evaporation method under Good Manufacturing Practice (GMP) conditions and are subsequently neutron activated in a nuclear reactor (Zielhuis et al. 2006a). Extensive animal studies have been conducted in which it was demonstrated that the toxicity profile of this microdevice is acceptable (Vente et al. 2008; Zielhuis et al. 2007). Also, the pharmaceutical quality has been investigated and found satisfactory (Zielhuis et al. 2006b; Zielhuis et al. 2006c).

Another issue to be addressed was assessment of the effects of the neutron irradiation on the microspheres integrity. Especially the accompanying decomposition damage caused by gamma photons and fast neutrons, and possibly by the thermal neutron capture side reactions, needs to be investigated (Yamaguchi and Waker 2007; Nijsen et al. 2002; Lin and Yeh 1966). Gamma irradiation is accompanied by both heating resulting from absorption of gamma-photon energy and by the formation of free radicals (Mader et al. 1996). The degree of damage that is inflicted upon the organic PLLA matrix is consequently dependent on the irradiation characteristics and irradiation time in a particular reactor facility. It is paramount to know exactly how long a typical patient dosage of ${ }^{165} \mathrm{Ho}$-PLLAMS (600 mg, 7.5-15 GBq) can be irradiated while remaining sufficiently intact for treatment of patients. In order to have sufficient time for transportation of the ${ }^{166}$ Ho-PLLA-MS from the reactor to the hospital, the microspheres must be neutron irradiated for a certain period of time. The minimum irradiation time is therefore dependent on logistics and the required amount of radioactivity to be instilled, consequently the thermal neutron flux. Conversely, the maximum irradiation time is set by the extent of irradiation damage that occurs. The aim of this research was to standardize and objectively validate the activation procedure in a particular reactor facility. Therefore, the maximum irradiation time of the ${ }^{165} \mathrm{Ho}$-PLLA-MS in a particular reactor was determined, and techniques that are applicable for routine quality control testing were defined. Methods used include photon and neutron energy deposition calculations, measurement of the thermal neutron flux, light microscopy, scanning electron microscopy, particle size analysis, molecular weight assessment using viscometry, and thermal analysis through differential scanning calorimetry.

\section{Materials and methods}

\subsection{Aim and study design}

1. To assess the maximum irradiation time, samples of microspheres of $600 \mathrm{mg}$ (typical patient dosage) consisting of ${ }^{165}$ Ho-PLLA-MS or PLLA-MS were neutron-irradiated for $0,2,4,6,7,8$, or $10 \mathrm{~h}$;

2. To assess whether differences in microsphere characteristics are observed, when neutron irradiation is carried out in different time slots of the reactor cycle, $600 \mathrm{mg}$ samples consisting of ${ }^{165} \mathrm{Ho}$-PLLA-MS were neutronirradiated for 6 or $7 \mathrm{~h}$, at the first section, half-way, and at the last section of the reactor cycle. The variation in microsphere quality within a week was investigated as well in 6-h irradiated ${ }^{166}$ Ho-PLLA-MS $(600 \mathrm{mg})$;

3. To assess whether self-shielding is a significant factor in the neutron activation, the generated amount of radioactivity was measured in samples of 50, 100, 200, 400,800 , and $1,000 \mathrm{mg}$ of ${ }^{166} \mathrm{Ho}$-PLLA-MS after neutron irradiation for $60 \mathrm{~min}$.

\subsection{Preparation of ${ }^{165} \mathrm{Ho}$-PLLA-MS and of PLLA-MS}

The preparation of GMP-grade ${ }^{165}$ Ho-PLLA-MS has been described in detail in a previous paper (Zielhuis et al. 2006a). In brief, holmium acetylacetonate (HoAcAc) and PLLA were dissolved in chloroform. This solution was sub- 
sequently emulsified in an aqueous solution of polyvinyl alcohol and, with the evaporation of the solvent, microspheres were formed. The microspheres were collected and fractionated according to size using stainless steel sieves. Except for deletion of the HoAcAc, the PLLAMS were produced in the same manner. The microspheres were collected and packed in high-density polyethylene (HDPE) vials (type A; Posthumus Plastics, Beverwijk, The Netherlands).

\subsection{Neutron irradiation procedure and neutron flux measurements}

Neutron flux monitors were placed on both ends of the vials packing the ${ }^{165}$ Ho-PLLA-MS or PLLA-MS. These neutron flux monitors were prepared from a certified chromium standard solution (NIST 3112a) and consisted of chromium $(0.52 \pm 0.03 \mathrm{mg})$ inside smaller HDPE vials (type V) (Koster-Ammerlaan et al. 2008). The vials were then wrapped in thin poly-ethylene foil and placed in a HDPE 'rabbit'-irradiation container (type XY) (Fig. 1(a)). The samples were irradiated in a pneumatic rabbit system facility of the nuclear reactor of the Delft University of Technology (Delft, The Netherlands) with a nominal thermal neutron flux of $5 \times 10^{16} \mathrm{~m}^{-2} \mathrm{~s}^{-1}$. The ${ }^{166} \mathrm{Ho}-$ PLLA-MS samples were allowed to decay for between 4 and 8 weeks before analysis of the samples.

The amount of radioactivity $\left({ }^{51} \mathrm{Cr}\right)$ in the flux monitors was measured through gamma-ray spectrometry, using a germanium detector and a 92X-II spectrum analyzer which was linked to a PC equipped with GammaVision ${ }^{\circledR}-32$ software, version 5.0 (EG \& G ORTEC, Oak Ridge, TN,
USA). Subsequently, the actual thermal neutron flux to which the flux monitors had been exposed was calculated using the following formula:

$$
\begin{aligned}
\varphi= & \frac{\lambda \cdot A_{320} \cdot m_{\mathrm{Cr}}}{N \cdot \sigma_{\mathrm{eff}} \cdot m \cdot \varepsilon \cdot \theta \cdot \gamma \cdot\left(1-e^{-\lambda \cdot t_{\mathrm{IRR}}}\right) \cdot e^{-\lambda \cdot t_{\mathrm{WT}}}\left(1-e^{-\lambda \cdot t_{\mathrm{CT}}}\right)} \\
& {\left[\mathrm{m}^{-2} \cdot \mathrm{s}^{-1}\right] }
\end{aligned}
$$

where

$\varphi \quad$ is the thermal neutron flux $\left(\mathrm{m}^{-2} \mathrm{~s}^{-1}\right)$

$\lambda \quad$ is the decay constant $\left(\ln 2 / \mathrm{T}_{1 / 2}\right)$ of ${ }^{51} \mathrm{Cr}$ : $2.896 \times 10^{-7} \mathrm{~s}^{-1}$

$A_{320}$ is the $320 \mathrm{keV}$ gamma peak area

$m_{\mathrm{Cr}}$ is the average atomic mass of chromium : $51.9961 \mathrm{~g} \mathrm{~mol}^{-1}$

$N \quad$ is the number of nuclei/mol (equal to Avogadro's number) : $6.022 \times 10^{23}$

$\sigma_{\text {eff }}$ is the effective activation cross section of ${ }^{50} \mathrm{Cr}$ : $1.53 \times 10^{-27} \mathrm{~m}^{2}$

$m \quad$ is the weight of chromium in the vial $(\mathrm{g})$

$\varepsilon \quad$ is the counting efficiency at $320 \mathrm{keV}$ (cps/dps)

$\theta \quad$ is the isotopic abundance of ${ }^{50} \mathrm{Cr}$ (ratio ${ }^{50} \mathrm{Cr} /\left({ }^{50} \mathrm{Cr}+{ }^{52} \mathrm{Cr}\right)$ ) : $4.35 \times 10^{-2}$

$\gamma \quad$ is the abundance of the $320 \mathrm{keV}$ gamma photon : $9.83 \times 10^{-2}$

$t_{\mathrm{IRR}}$ is the neutron irradiation time (s)

$t_{\mathrm{WT}} \quad$ is the waiting time between neutron activation and spectrometry measurement (s)

$t_{\mathrm{CT}} \quad$ is the spectrometry measurement time (s)

Since the samples were located in the bottom half of the vials, the effective neutron flux to which a sample is
Fig. 1 (a) Schematic representation of the HDPE 'rabbit' type irradiation container ( 1 ) containing the neutron flux monitors (2) on top and bottom of the vial that contains a sample of

${ }^{165}$ Ho-PLLA-MS or PLLA-MS

(3). The flux monitors and the vial containing the sample are wrapped in poly-ethylene foil (4); (b) schematic representation of the pneumatic rabbit system (1) with the 'rabbit' at the distal end of the system (2), next to the reactor core of the Delft reactor, which is composed of fuel rods $\left(\mathrm{U}_{3} \mathrm{Si}_{2}-\mathrm{Al}\right)(3)$, borium-carbide control rods, $73.3 \%$ removed (4), and beryllium reflector elements (5)
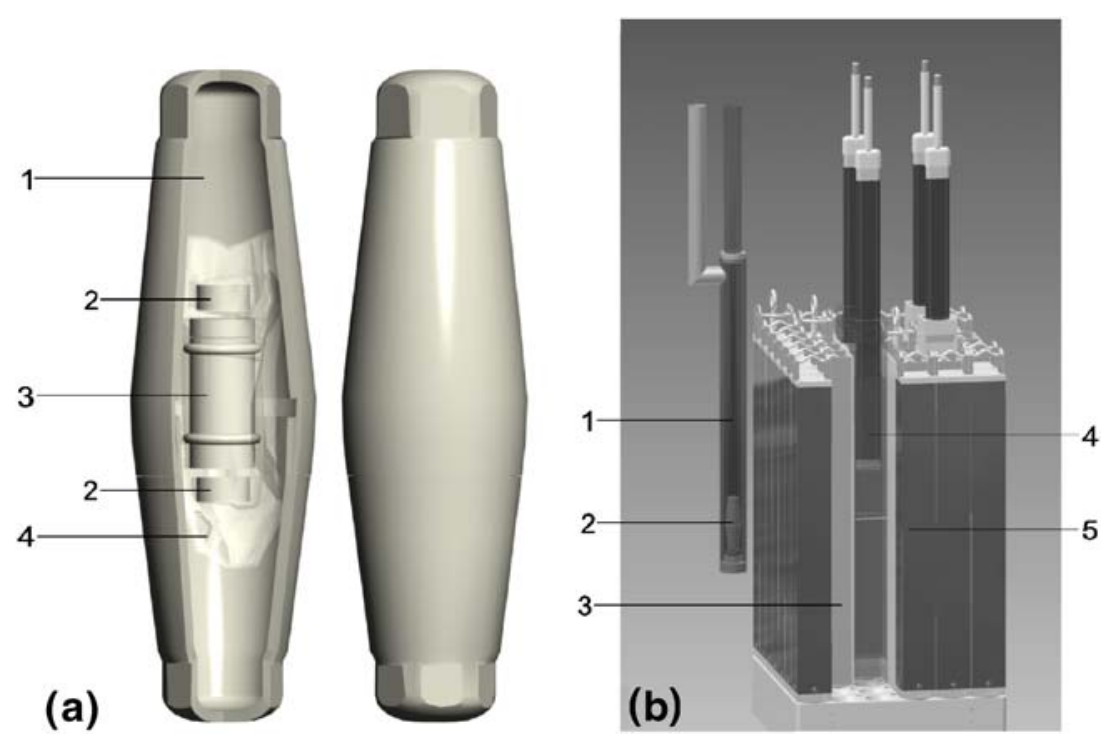
exposed can be calculated, using linear interpolation, as follows:

$$
\varphi_{\text {eff }}=\left(1 / 3 \cdot \varphi_{\text {monitor 1 }}\right)+\left(2 / 3 \cdot \varphi_{\text {monitor } 2}\right) \quad\left[\mathrm{m}^{-2} \mathrm{~s}^{-1}\right]
$$

where

$\varphi_{\text {eff }} \quad$ is the effective neutron flux

$\varphi_{\text {monitor }_{1}}$ is the neutron flux measured by the monitor placed on top of the vial

$\varphi_{\text {monitor }}$ is the neutron flux measured by the monitor placed on the bottom of the vial

\subsection{Energy deposition calculations}

Energy spectra and energy depositions of neutrons and photons in the irradiation facility were calculated using the stochastic transport Monte Carlo method based code MCNP5 (X-5 Monte Carlo Team 2003). The code can be used in several transport modes: neutron only, photon only, or combined neutron/photon transport where the photons are produced by neutron interactions. In the calculations described here, the combined neutron/photon mode was used. The neutron energy regime was from $10^{-11}$ to $20 \mathrm{MeV}$ for all isotopes, and the photon energy regime was from $1 \mathrm{keV}$ to $100 \mathrm{GeV}$.

The model describes the fuel assemblies in the Delft reactor by individual fuel plates and uses 15 axial regions along the height of the fuel. Each movable beryllium reflector element was modeled separately. All the existing beam tubes and irradiation facilities near the core were represented in the model. The material composition of the fuel was given per fuel assembly and per axial region. The burn-up dependent fuel composition was determined separately. The material composition was determined for three cases with full xenon equilibrium:

1. Begin of cycle, after 12 megawatt-days (MWD) at full power, with the control rods at $73.30 \%$ removed (Fig. 1(b));

2. Half-way of cycle, after 68 MWD of full power, with the control rods at $81.30 \%$ removed;

3. End of cycle, after 130 MWD at full power, with the control rods at $97.03 \%$ removed.

The depletion of beryllium and the photo-neutron production in beryllium were neglected. For the calculations the ENDF/B-VI data library was used as distributed with the MCNP5 package. The model has been validated on a recent Delft reactor configuration (2008) by comparing the reactivity and the measured axial distribution of ${ }^{59} \mathrm{Co}$ $(n, \gamma){ }^{60} \mathrm{Co}$ reaction rates. The average value of this $\mathrm{Co}$ activation measurement was used for power normalization, the ratio of the total power to fission power was assumed to be constant during the whole cycle. The aluminum tube of the pneumatic rabbit system and the HDPE rabbit vial were included in the calculations.

2.5 Particle size distribution, light microscopy and scanning electron microscopy (SEM)

The particle size distributions (volume percentage) of the non-irradiated samples (the control samples: ${ }^{165}$ Ho-PLLAMS and PLLA-MS) and the irradiated samples $\left({ }^{166} \mathrm{Ho}-\right.$ PLLA-MS and PLLA-MS) were determined using a Coulter Counter Multisizer 3 apparatus (Beckman Coulter Nederland, Mijdrecht, The Netherlands), equipped with a $100-\mu \mathrm{m}$ aperture tube. The preset quality criteria were set at minimally 95 vol.\% between $15-60 \mu \mathrm{m}$, and 92 vol.\% between 20-50 $\mu \mathrm{m}$. Microsphere morphology, i.e. the extent of damage, was evaluated using light microscopy. The surface morphology was investigated by SEM using a Phenom ${ }^{\circledR}$ electron microscope (FEI Electron Optics, Eindhoven, The Netherlands). Samples were mounted on aluminum stubs and sputter-coated with a Pt layer of $6 \mathrm{~nm}$.

\subsection{Modulated differential scanning calorimetry (MDSC)}

Thermal analysis was performed using a DSC Q1000 (TA Instruments Inc., New Castle, DE, USA). Samples of $6 \mathrm{mg}$ of ${ }^{165}$ Ho-PLLA-MS, ${ }^{166}$ Ho-PLLA-MS, and non-irradiated and irradiated PLLA-MS were transferred into aluminum pans which were then hermetically sealed. The samples were heated from $20^{\circ} \mathrm{C}$ to $220^{\circ} \mathrm{C}$ at a rate of $2^{\circ} \mathrm{C} \mathrm{min}{ }^{-1}$. The measurements were analyzed using Universal Analysis 2000 software (version 3.9A; TA Instruments Inc., New Castle, DE, USA).

\subsection{Viscometry}

The molecular weight was determined in the Ho-PLLA-MS samples $(0,2,4,6,8,10 \mathrm{~h}$ irradiated), PLLA-MS samples $(0,2,4,6,7,8,10 \mathrm{~h}$ irradiated), and non-irradiated PLLA standards (obtained from PURAC biochem B.V., Gorinchem, The Netherlands) using dilute-solution viscometry. The samples were dissolved in chloroform, and the measurements were conducted at $25^{\circ} \mathrm{C}$, using a Ubbelohde capillary viscometer, as described in the literature (Omelczuk and McGinity 1992).

\subsection{Sterility of the ${ }^{166}$ Ho-PLLA-MS}

To test the sterility of the microspheres, samples of $450 \mathrm{mg}$ of ${ }^{165}$ Ho-PLLA-MS, spiked with Bacillus pumilis spores as a biological indicator, were neutron irradiated for $6 \mathrm{~h}$. Then, the samples were tested for bacterial contamination by a certified company (Bactimm B.V., Nijmegen, The Netherlands). 
(a)

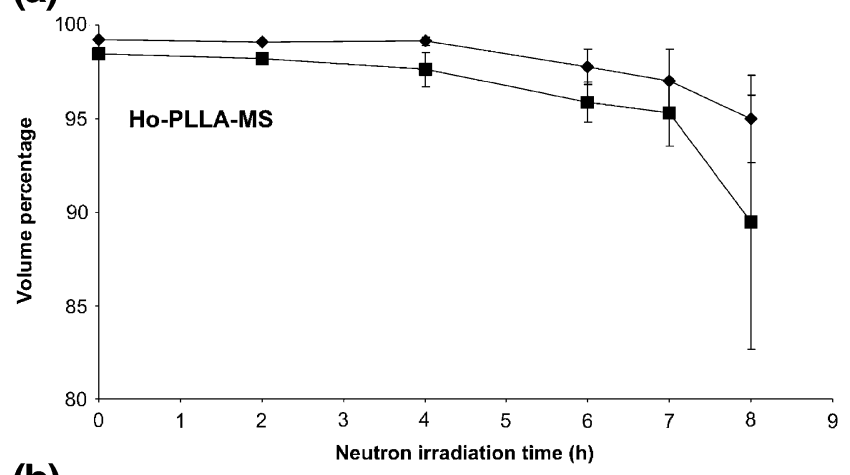

(b)

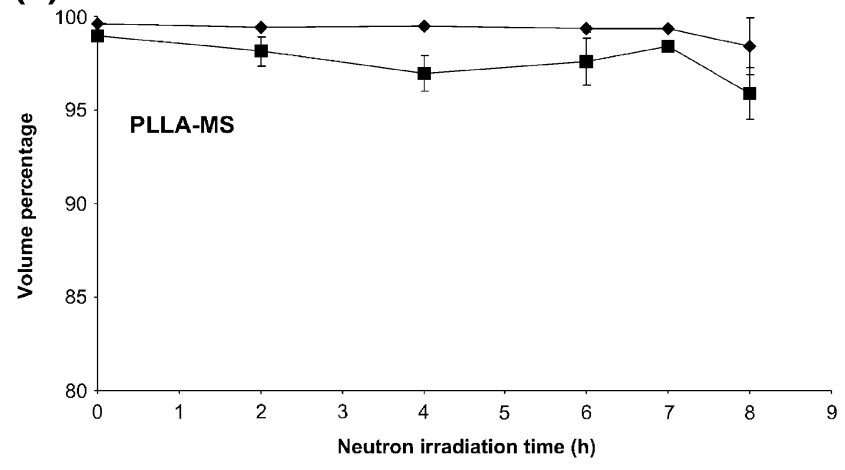

Fig. 2 (a) Mean particle size $( \pm \mathrm{SD})$ of the Ho-PLLA-MS, neutronirradiated for $0,2,4,6,7$, or $8 \mathrm{~h}$; (b) mean particle size $( \pm \mathrm{SD})$ of the PLLA-MS, neutron-irradiated for $0,2,4,6,7$, or 8 h (diamond 15$60 \mu \mathrm{m}$; square $20-50 \mu \mathrm{m})$

\section{Results and discussion}

3.1 Particle size distribution, light microscopy and scanning electron microscopy (SEM)

Particle size analysis was performed on all samples (Fig. 2). For detailed information on microsphere morphology, light microscopy and SEM were employed (Figs. 3 and 4).

The particle size analyses of the ${ }^{166} \mathrm{Ho}-\mathrm{PLLA}-\mathrm{MS}$ showed that the required size distribution was guaranteed up to neutron irradiation for $7 \mathrm{~h}$ (Fig. 2(a)). Both light microscopic and SEM analysis showed that differences in morphology were hardly detectable between samples irradiated for 0,2 , and $4 \mathrm{~h}$, with microspheres of these samples all exhibiting a smooth, intact surface (Figs. 3(a-c) and 4(a-c)). Although the surface of 6- and 7-h irradiated ${ }^{166}$ Ho-PLLA-MS displayed some damage, the morphology of the microspheres was quite similar to that of the nonirradiated samples (Figs. 3(d-e) and 4(d-e)). Microsphere quality clearly decreased when exposed for a 8 -h irradiation period as small dents on the surface and a lot of fragments were visible (Figs. 3(f) and 4(f)). In addition, the particle size distribution was insufficient (Fig. 2(a)). Light microscopy and SEM of the 10-h irradiated ${ }^{166}$ Ho-PLLA-MS revealed extensively damaged microspheres, only barely spherical in shape (Figs. 3(g) and 4(g)). Particle size analyses of these samples proved impossible due to blockage of the apparatus' probe aperture as a consequence of the formation of particle agglomerates.

To assess the possible effects on microsphere quality after neutron irradiation in different slots of the reactor cycle, ${ }^{165}$ Ho-PLLA-MS were irradiated for 6 or $7 \mathrm{~h}$ in the first, in the middle, and in the last section of the reactor cycle. These samples all met the preset particle size criteria (Fig. 5). The nuclear reactor explored in this study is a research reactor which is started up each Monday and shut off each Friday. Samples of ${ }^{165}$ Ho-PLLA-MS were irradiated on Tuesdays, Wednesdays and Thursdays. No differences in quality were observed; they all met the required specifications.

For the PLLA-MS, particle size distribution was slightly better than for the ${ }^{166} \mathrm{Ho}-\mathrm{PLLA}-\mathrm{MS}$ (Fig. 2); the desired size distribution was maintained after $8 \mathrm{~h}$ of neutron irradiation. The PLLA-MS samples that were irradiated 0 , 2,4 , and $6 \mathrm{~h}$ all remained completely spherical with an intact surface as observed by light microscopy and SEM (Figs. 3(h-k) and 4(h-k)). However, careful examination of the light micrographs and (especially) SEM images of the
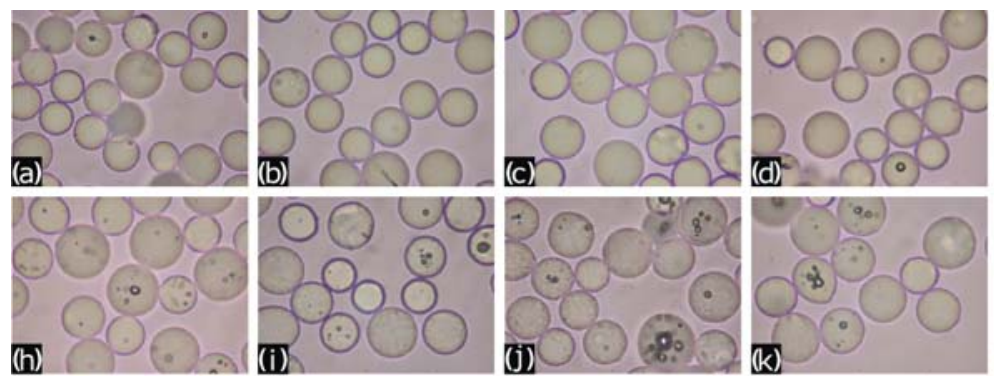
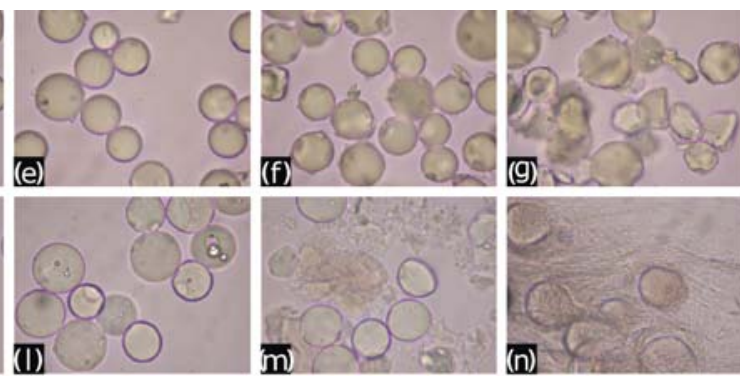

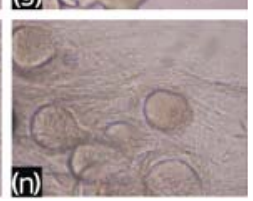

Fig. 3 (a-g) Light micrographs of Ho-PLLA-MS, neutron-irradiated for $0,2,4,6,7,8$, or $10 \mathrm{~h}$. In samples irradiated up to $7 \mathrm{~h}$ damage is absent or minor (a-e). The damage observed in the 8 -h irradiated microspheres and in particular the $10-\mathrm{h}$ irradiated microspheres is characterized by crumbles and breaking $(\mathbf{f}-\mathbf{g}) ;(\mathbf{h}-\mathbf{n})$ light micrographs of PLLA-MS, neutron-irradiated for $0,2,4,6,7,8$, or $10 \mathrm{~h}$. In samples irradiated up to $7 \mathrm{~h}$ damage is again absent or minor $(\mathbf{h}-\mathbf{l})$. The 8-h irradiated microspheres reveal signs of melting, whereas in the 10-h irradiated samples most microspheres have melted and only sporadically some remnants of microspheres can be seen $(\mathbf{m}-\mathbf{n})$ 

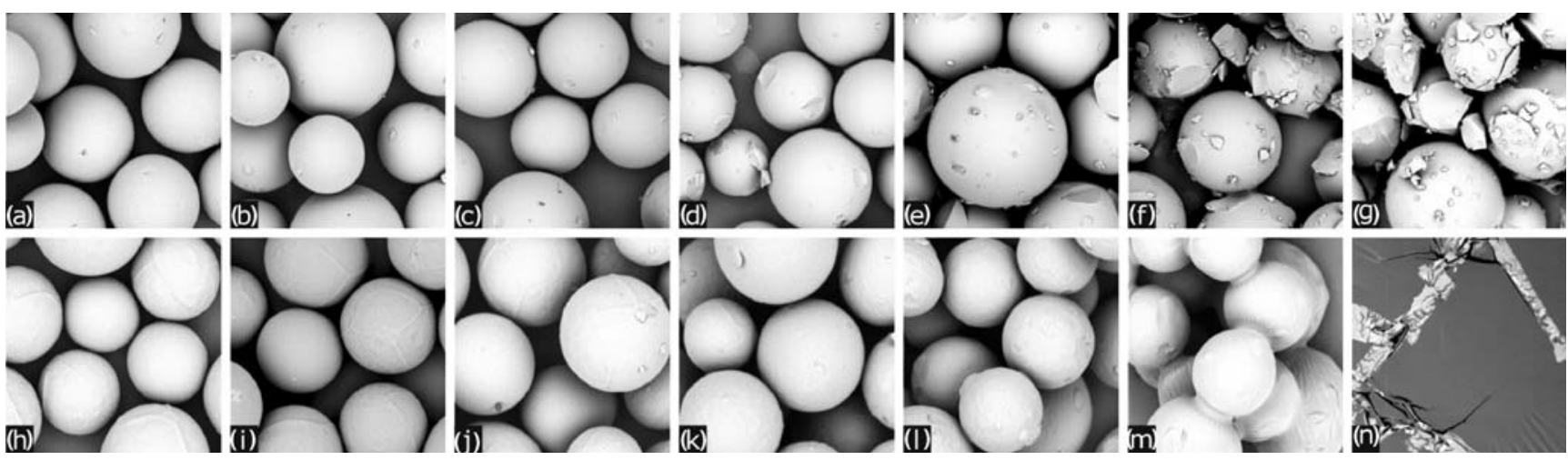

Fig. 4 (a-g) Scanning electron micrographs of Ho-PLLA-MS, neutron-irradiated for $0,2,4,6,7,8$, or $10 \mathrm{~h}$. In samples irradiated up to $7 \mathrm{~h}$ damage is absent or minor $(\mathbf{a}-\mathbf{e})$. On the dented surface of the 8-h irradiated microspheres small microsphere fragments are seen (f). Disintegration has progressed in the 10-h irradiated microspheres with many microspheres actually having been broken into several large chunks, and many smaller fragments visible as well $(\mathbf{g}) ;(\mathbf{h}-\mathbf{n})$ scanning electron micrographs of PLLA-MS, neutron-irradiated for 0 , $2,4,6,7,8$, or $10 \mathrm{~h}$. In samples irradiated up to $6 \mathrm{~h}$ damage is absent (h-k). In the 7-h irradiated samples a tendency to interfusion is observed (l). Microsphere fusion is more frequently seen in the 8-hirradiated samples $(\mathbf{m})$. In the 10-h irradiated samples microspheres had completely melted, and no identifiable remnants of microspheres were found (n) 7-h irradiated samples gave indications that the surfaces had partially liquefied (Fig. 4(1)). This 'melting' was more prominently visible on SEM images of the 8-h irradiated PLLA-MS samples which occasionally showed that microspheres had started to fuse (Fig. 4(m)). Ten-hour irradiation yielded PLLA-MS which had been destroyed (Figs. 3(n) and 4(n)). Particle size measurements of the latter samples were impossible since they had basically been turned into a solitary piece of an adhesive substance. In contrast to the light micrograph where a few sphere-like structures were

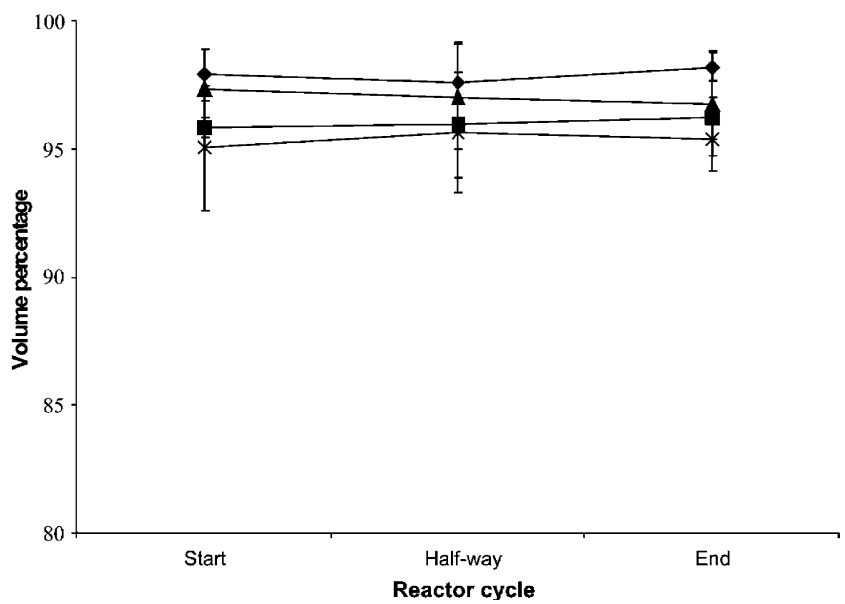

Fig. 5 Mean particle size ( \pm SD) of duplo samples of ${ }^{166}$ Ho-PLLAMS neutron-irradiated for 6 or $7 \mathrm{~h}$ at the first section, half-way, and at the last section of the reactor cycle. Particle size was invariably within the required specifications during the different time slots of the reactor

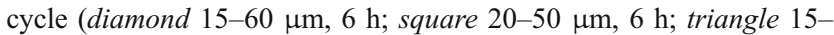
$60 \mu \mathrm{m}, 7 \mathrm{~h}$; multiplication symbol 20-50 $\mu \mathrm{m}, 7 \mathrm{~h}$ ) still detectable, no spherical shape was found using SEM, which may be due to sample preparation for SEM.

\subsection{Energy deposition and neutron flux}

Irradiation induced damage as a consequence of energy deposition can be a problem in the production of ${ }^{166} \mathrm{Ho}-$ PLLA-MS. Therefore, energy deposition was calculated for both neutrons and photons. The calculated total energy deposition showed a small decrease during the reactor cycle (Table 1). More than $93 \%$ of the total energy deposition came from the photons. This is in accordance with previous experimental findings which indicated that damage to the ${ }^{166} \mathrm{Ho}-\mathrm{PLLA}-\mathrm{MS}$ is due mainly to gamma radiation (Zielhuis et al. 2006c).

Like the 'gamma heating' the thermal neutron flux measurements showed a slight decrease during the reactor cycle (Fig. 6). The thermal neutron flux measured using $\mathrm{Cr}$ monitors on top of the vials was $6.8 \%$ higher than measured by the monitors on the vial bottoms $(5.21 \pm 0.24$ and $4.88 \pm$ $0.28 \times 10^{16} \mathrm{~m}^{-2} \mathrm{~s}^{-1}$ (mean $\left.\pm \mathrm{SD}\right)$, respectively). The effective thermal neutron flux was $4.99 \pm 0.23 \times 10^{16} \mathrm{~m}^{-2} \mathrm{~s}^{-1}$ (mean \pm $\mathrm{SD})$. Without any correction for the variation of flux during the reactor cycle the above would implicate that for a requested patient dosage of $7.5 \mathrm{GBq}{ }^{166} \mathrm{Ho}$ the actually produced amount of radioactivity may vary between 6.8 and $8.2 \mathrm{GBq}$ in $95 \%$ of cases. The consequence would be that a liver absorbed dose intended to be 80 Gy would vary between 73 and $87 \mathrm{~Gy}$. This variation is accepted common practice in nuclear medicine.

To identify whether facilities in other nuclear reactors could be used for routine production of ${ }^{166} \mathrm{Ho}$-PLLA-MS, 
Table 1 Energy depositions delivered on microspheres during neutron irradiation

\begin{tabular}{ll}
\hline Reactor cycle time slot & Energy deposition $\left(10^{13} \mathrm{MeV} / \mathrm{g} \mathrm{h}\right)$ \\
\hline & Neutrons \\
Begin & $7.63 \pm 0.48$ \\
Mid & $7.34 \pm 0.45$ \\
End & $7.73 \pm 0.52$ \\
& Photons \\
Begin & $112.0 \pm 4.7$ \\
Mid & $111.4 \pm 6.8$ \\
End & $106.2 \pm 5.0$ \\
& Neutrons + photons \\
Begin & $119.7 \pm 5.2$ \\
Mid & $118.7 \pm 7.0$ \\
End & $113.9 \pm 5.5$ \\
\hline
\end{tabular}

Values are presented as mean $\pm \mathrm{SD}$

the energy deposition by neutrons and, particularly, photons, can be calculated and related to the thermal neutron flux.

\subsection{Linearity of the activated fraction}

In order to determine whether self-shielding occurs, i.e. to assess the relation between the amount of microspheres irradiated and amount of radioactivity produced, ascending amounts of ${ }^{165}$ Ho-PLLA-MS (50-1,000 mg) were irradiated for $60 \mathrm{~min}$. The specific activity $(\mathrm{MBq} / \mathrm{mg})$ was found to be linearly related to the amount of microspheres (Fig. 7). Coefficient of variance was only $2.6 \%(4.53 \pm 0.12 \mathrm{MBq} / \mathrm{mg})$. Neutron irradiation time does therefore not need to be adjusted for different amounts of ${ }^{165}$ Ho-PLLA-MS.

\subsection{Modulated differential scanning calorimetry}

Both PLLA-MS and Ho-PLLA-MS, neutron irradiated for $0,2,4,6,7,8$, or $10 \mathrm{~h}$, were analyzed by MDSC (Table 2). Irradiation of PLLA-MS resulted in a decrease in melting temperature $\left(T_{\mathrm{m}}\right)$ and decreased enthalpy of fusion $\left(\Delta H_{\mathrm{m}}\right)$ with increasing irradiation time, indicating impairment of the crystalline phase of the PLLA matrix inflicted by the neutron irradiation. The $T_{\mathrm{m}}$ of non-irradiated PLLA-MS was $179 \pm 0^{\circ} \mathrm{C}$ and decreased to $113 \pm 5^{\circ} \mathrm{C}$ for $6 \mathrm{~h}$ irradiated samples. The $\Delta H_{\mathrm{m}}$ for fully crystalline monodisperse lactic acid oligomers amounted to $93 \mathrm{~J} / \mathrm{g}$ (De Jong et al. 1998). The $\Delta H_{\mathrm{m}}$ for non-irradiated PLLA-MS was $57 \pm 6 \mathrm{~J} / \mathrm{g}$, and decreased to $14 \pm 12 \mathrm{~J} / \mathrm{g}$ after $6 \mathrm{~h}$ irradiation signifying that crystallinity decreased by roughly $75 \%$. After $7 \mathrm{~h}$ of neutron irradiation and longer no melting peak in the DSC thermogram was observed, indicating a complete loss of crystallinity. The glass transition temperature $\left(T_{\mathrm{g}}\right)$ decreased from $68^{\circ} \mathrm{C}$ to around $50^{\circ} \mathrm{C}$ after irradiation, and was nondetectable after irradiation for $7 \mathrm{~h}$ and longer, which is consistent with previously reported findings (Zielhuis et al. 2006c). These findings indicate that after irradiation of $7 \mathrm{~h}$ structural changes of the polymer matrix occurred. This is consistent with light microscopy and SEM analysis which revealed the onset of surface changes at $7 \mathrm{~h}$ irradiation (Fig. 4(1)). ${ }^{165}$ Ho-PLLA-MS showed a lower $T_{\mathrm{m}}$ and $\Delta H_{\mathrm{m}}$ compared to non-irradiated PLLA-MS $\left(148 \pm 5^{\circ} \mathrm{C}\right.$ and $9 \pm$ $4 \mathrm{~J} / \mathrm{g}$ vs. $179 \pm 0^{\circ} \mathrm{C}$ and $\left.57 \pm 6 \mathrm{~J} / \mathrm{g}\right)$. This is in accordance with previously reported findings and was ascribed to interaction of the carbonyl groups of PLLA with the holmium ion of the HoAcAc complex (Nijsen et al. 2002). After neutron irradiation of $2 \mathrm{~h}$ and longer no melting transitions were observed in the ${ }^{166}$ Ho-PLLA-MS thermographs, indicating absence of crystallinity. Glass transition was present in the thermographs of the non-
Fig. 6 Effective thermal neutron flux measurements at the first section, middle-section, and at the last section of the reactor cycle (mean $\pm \mathrm{SD}$, $n=12 /$ section). A slight decline in flux is observed

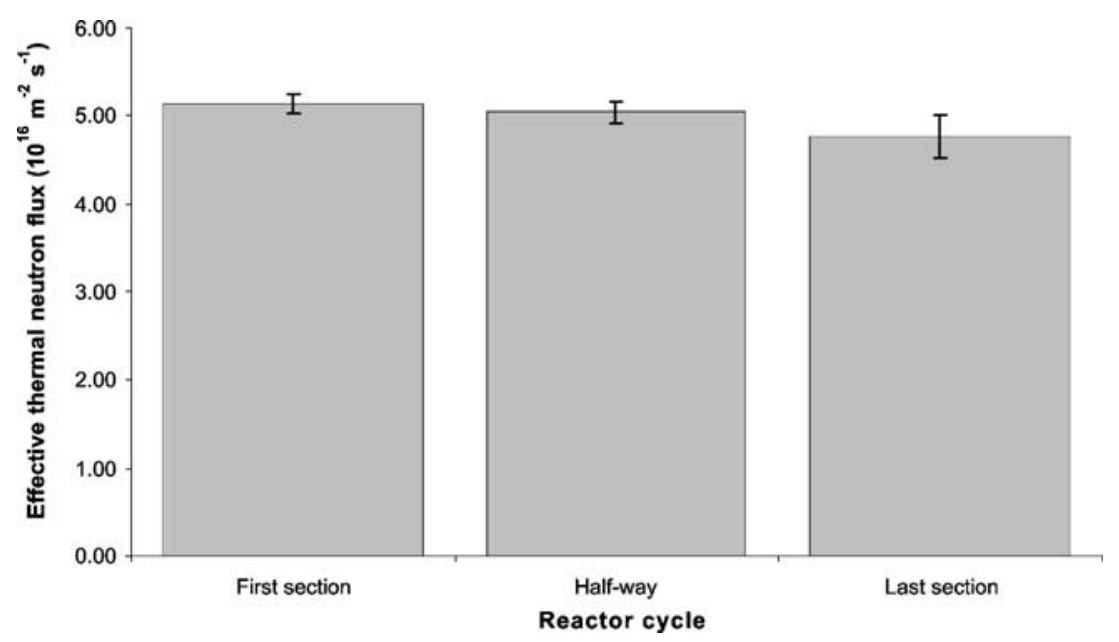




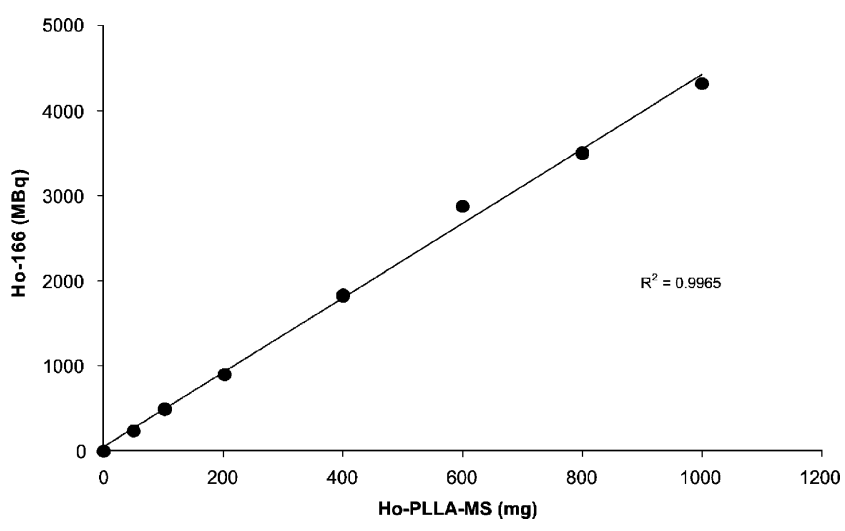

Fig. 7 Generated amounts of radioactivity (end-of-bombardment) plotted against ascending amounts of ${ }^{166}$ Ho-PLLA-MS following neutron activation for $60 \mathrm{~min}$. A linear relation is observed demonstrating that no self-shielding occurs in higher amounts of microspheres

irradiated and all irradiated Ho-PLLA-MS samples, whereas in the PLLA-MS samples glass transition was absent after irradiation for $7 \mathrm{~h}$ and longer.

\subsection{Viscometry}

The molecular weight of PLLA-MS, neutron-irradiated for $0,2,4,6,7,8$, or $10 \mathrm{~h}$, and Ho-PLLA-MS, irradiated for 0 , 2 , 4 , or $6 \mathrm{~h}$, was determined using dilute-solution viscometry. ${ }^{166}$ Ho-PLLA-MS irradiated for 7,8 , or $10 \mathrm{~h}$ were not included in this analysis because these samples only partially dissolved in chloroform. A major difference in molecular weight was observed between the nonirradiated PLLA-MS and ${ }^{165}$ Ho-PLLA-MS. The measured molecular weight of the PLLA in the ${ }^{165}$ Ho-PLLA-MS was less than $40 \%$ that of the PLLA in the PLLA-MS. This apparent lower molecular weight of the PLLA is most likely due to the above mentioned interaction between PLLA and HoAcAc and is in agreement with previously published results on gel permeation chromatography analysis of PLLA-MS and Ho-PLLA-MS samples (Nijsen et al. 2002). After $2 \mathrm{~h}$ of irradiation the molecular weight in the samples of both categories had already decreased strongly (approximately 70\%), as a consequence of radiationinduced chain scissions. After $6 \mathrm{~h}$ of irradiation and longer the molecular weight had decreased by over $90 \%$. In spite of this dramatic loss of PLLA chain length, the structural integrity was guaranteed up to $7 \mathrm{~h}$ (see Section 3.1). It was found in previous studies that providing the microspheres had remained intact, a decrease in molecular weight is not associated with a clinically relevant release of radioactivity $(<1 \%)$ (Zielhuis et al. 2006b; Nijsen et al. 2002; Van Es et al. 2001).

\subsection{Sterility of the ${ }^{166}$ Ho-PLLA-MS}

After neutron irradiation, samples spiked with spores of B. pumilis were tested for viable bacteria. Colony forming units were detected only in the spiked, non-irradiated sample. The finding that no viable bacteria were present in the irradiated samples spiked with spores of $B$. pumilis was expected since the $D$-value $(90 \%$ kill value) of $B$. pumilis spores is $<2 \mathrm{kGy}$ (Prince 1978) and the gamma dose delivered on the sample was over 30 times higher than the dose used in routine gamma-radiation sterilization (840 $\mathrm{kGy} \mathrm{h}^{-1}$ and $25 \mathrm{kGy}$ (minimum absorbed dose (European Directorate for the Quality of Medicines \& HealthCare 2008), respectively). Since the samples had been irradiated for $6 \mathrm{~h}$ the delivered gamma dose was in excess of 5,000 kGy.
Table 2 Transition temperatures of Ho-PLLA-MS and PLLA-MS $(n=4-8)$ nd not detectable, $T_{g}$ glass transition temperature, $T_{c}$ recrystallization temperature, $\Delta H_{c}$ enthalpy of the recrystallization, $T_{m}$ melting temperature, $\Delta H_{m}$ enthalpy of fusion

\begin{tabular}{lllllll}
\hline Irradiation time (h) & Sample description & $T_{\mathrm{g}}\left({ }^{\circ} \mathrm{C}\right)$ & $T_{\mathrm{c}}\left({ }^{\circ} \mathrm{C}\right)$ & $\Delta H_{\mathrm{c}}(\mathrm{J} / \mathrm{g})$ & $T_{\mathrm{m}}\left({ }^{\circ} \mathrm{C}\right)$ & $\Delta H_{\mathrm{m}}(\mathrm{J} / \mathrm{g})$ \\
\hline 0 & PLLA-MS & $68 \pm 3$ & $152 \pm 1$ & $5 \pm 0$ & $179 \pm 0$ & $57 \pm 6$ \\
2 & PLLA-MS & $50 \pm 2$ & $80 \pm 1$ & $28 \pm 1$ & $150 \pm 1$ & $40 \pm 2$ \\
4 & PLLA-MS & $43 \pm 8$ & $\mathrm{nd}$ & $\mathrm{nd}$ & $131 \pm 1$ & $25 \pm 5$ \\
6 & PLLA-MS & $54 \pm 1$ & $\mathrm{nd}$ & $\mathrm{nd}$ & $113 \pm 5$ & $14 \pm 12$ \\
7 & PLLA-MS & nd & nd & nd & nd & nd \\
8 & PLLA-MS & nd & nd & nd & nd & nd \\
10 & PLLA-MS & nd & nd & nd & nd & nd \\
0 & Ho-PLLA-MS & $65 \pm 2$ & $123 \pm 14$ & $9 \pm 6$ & $148 \pm 5$ & $9 \pm 4$ \\
2 & Ho-PLLA-MS & $52 \pm 3$ & nd & nd & nd & nd \\
4 & Ho-PLLA-MS & $55 \pm 3$ & nd & nd & nd & nd \\
6 & Ho-PLLA-MS & $54 \pm 5$ & nd & nd & nd & nd \\
7 & Ho-PLLA-MS & $55 \pm 3$ & nd & nd & nd & nd \\
8 & Ho-PLLA-MS & $58 \pm 5$ & nd & nd & nd & nd \\
10 & Ho-PLLA-MS & $58 \pm 2$ & nd & nd & nd & nd \\
\hline
\end{tabular}




\subsection{Nuclear reactor testing strategy}

The strategy consisted of several techniques and calculations to determine whether the Delft nuclear reactor is suitable for neutron activation of ${ }^{165}$ Ho-PLLA-MS. Obviously, for reasons of logistics, upscaling and flexibility, it is important to explore whether other reactors in the world are available, and suitable, for this purpose.

In order to screen a reactor (facility) for its suitability for neutron activating ${ }^{165}$ Ho-PLLA-MS, it is recommended to start with measurements of the thermal neutron flux and calculations of the total energy deposition. The thermal neutron flux $\left(\mathrm{n} / \mathrm{cm}^{2} \mathrm{~h}\right) /$ total energy deposition $(\mathrm{MeV} / \mathrm{g} \bullet \mathrm{h})$ ratio can then be calculated. For the Delft reactor this ratio is 15 . Thus, a ratio of 15 or higher implies that ${ }^{166}$ Ho-PLLA-MS of acceptable quality can expectedly be produced. If the ratio is adequate, irradiations of a few $600 \mathrm{mg}$-samples of ${ }^{165} \mathrm{Ho}$-PLLA-MS are to be carried out to assess the maximum activation time. The quality of the ${ }^{166}$ Ho-PLLA-MS ought to be evaluated by light microscopy and particle size analysis. If the microspheres are of sufficient quality, SEM should be carried out. Subsequently, the reactor conditions and variations in time are to be investigated in more detail, viz. stability of the neutron flux. PLLA-MS respond differently to neutron irradiation compared to ${ }^{165}$ Ho-PLLA-MS, as was discussed in Section 3.1. However, the maximally tolerable irradiation time of the two types of microspheres was of the same order. It is therefore suggested that initial screening of a reactor (facility) is carried out with PLLA-MS since these particles do not become radioactive which permits carefree handling and analysis carried out immediately after neutron irradiation. Apart from reactor screening and validation, some of the methods discussed in this paper are also applicable for quality control, which is extremely important with regard to this highly radioactive microdevice. For instance, it is proposed that after irradiation a small sample is evaluated by light microscopy and/or particle size analysis.

\section{Conclusions}

It is concluded that ${ }^{165}$ Ho-PLLA-MS can endure neutron activation in the Delft nuclear reactor up to $7 \mathrm{~h}$ and still maintain their structural integrity. After neutron activation for $7 \mathrm{~h}$ the generated activity in a typical patient dosage of $600 \mathrm{mg}$ of ${ }^{166}$ Ho-PLLA-MS is high enough to allow for sufficient time for transportation to the hospital and also high enough to deliver liver absorbed doses in the tumoricidal range. Furthermore, in this reactor, the two most important reactor condition parameters, neutron flux and gamma heating, are relatively constant in time, allowing for the routine production of ${ }^{166}$ Ho-PLLA-MS of a consistent quality.
Structural integrity was preserved after at least 7 h-neutron irradiation even though the poly(L-lactic acid) matrix of this microdevice is in fact relatively sensitive to neutron irradiation, specifically the accompanying gamma heating. DSC measurements showed that the crystalline structure was lost completely between 0 and $2 \mathrm{~h}$ of irradiation. Viscometry analysis also showed that chain length decreases rapidly during neutron irradiation, yet microscopically the microspheres' surface remained virtually intact and particle size distribution was acceptable after irradiation of $7 \mathrm{~h}$.

The activated fraction was independent of the amount of ${ }^{165}$ Ho-PLLA-MS that was neutron activated, meaning no self-shielding had occurred, at least up to the maximum patient dosage of 1,000 mg. As expected, both spiked and unspiked samples of ${ }^{166}$ Ho-PLLA-MS were sterile after neutron irradiation.

Neutron flux measurements and energy deposition calculations are required in the screening of other nuclear reactors. For the evaluation of microsphere quality, not only in reactor screening but also in routine quality control, light microscopy, SEM and particle size analysis are appropriate techniques.

Acknowledgements Financial support by the Dutch Technology Foundation STW under grant UGT.6069 is gratefully acknowledged.

Conflict of interest statement The authors have no conflicts of interest to report.

Open Access This article is distributed under the terms of the Creative Commons Attribution Noncommercial License which permits any noncommercial use, distribution, and reproduction in any medium, provided the original author(s) and source are credited.

\section{References}

Bierman, H. R., Byron, R. L., Jr., Kelley, K. H., Grady, A. J. (1951). National Cancer Institute 12, 107-131

De Jong, S., Van Dijk-Wolthuis, W. N. E., Kettenes-van den Bosch, J. J., Schuyl, P. J. W., Hennink, W. E. (1998). Macromolecules 31, 6397-6402. doi:10.1021/ma980553i

De Wit, T. C., Xiao, J., Nijsen, J. F., van het Schip, F. D., Staelens, S. G., van Rijk, P. P., Beekman, F. J. (2006). Phys. Med. Biol. 51, 4773-4787. doi:10.1088/0031-9155/51/19/004

European Directorate for the Quality of Medicines \& HealthCare, European Pharmacopoeia, 6th edn, Suppl. 6.3, Par. 5.1.1. (2008)

Gomaa, A. I., Khan, S. A., Toledano, M. B., Waked, I., TaylorRobinson, S. D. (2008). World J. Gastroenterol. 14, 4300-4308. doi:10.3748/wjg. 14.4300

Gulec, S. A., Fong, Y. (2007). Arch. Surg. 142, 675-682. doi:10.1001/ archsurg.142.7.675

Koster-Ammerlaan, M. J., Bacchi, M. A., Bode, P., De Nadai Fernandes, E. A. (2008). Appl. Radiat. Isotopes 66, 1964-1969. doi:10.1016/j.apradiso.2008.06.001

Lin, T. K., Yeh, S. J. (1966).J. Nucl. Med. Technol. 3, 289-293. doi: $10.3327 /$ jnst.3.289 
Mader, K., Domb, A., Swartz, H. M. (1996). Appl. Radiat. Isotopes 47, 1669-1674. doi:10.1016/S0969-8043(96)00236-9

Nijsen, J. F. W., van Steenbergen, M. J., Kooijman, H., Talsma, H., Kroon-Batenburg, L. M., van de Weert, M., van Rijk, P. P., de Witte, A., van het Schip, A. D., Hennink, W. E. (2001). Biomaterials 22, 3073-3081. doi:10.1016/S0142-9612(01)00055-2

Nijsen, J. F. W., van het Schip, A. D., van Steenbergen, M. J., Zielhuis, S. W., Kroon-Batenburg, L. M., van de Weert, M., van Rijk, P. P., Hennink, W. E. (2002). Biomaterials 23, 1831-1839. doi:10.1016/S0142-9612(01)00309-X

Nijsen, J. F., Seppenwoolde, J. H., Havenith, T., Bos, C., Bakker, C. J., van het Schip, A. D. (2004). Radiology 231, 491-499. doi:10.1148/radiol.2312030594

Omelczuk, M. O., McGinity, J. W. (1992). Pharm. Res. 9, 26-32. doi:10.1023/A:1018967424392

Parkin, D. M., Bray, F., Ferlay, J., Pisani, P. (2005). CA Cancer J. Clin. 55, 74-108. doi:10.3322/canjclin.55.2.74

Prince, H. N. (1978). Appl. Environ. Microbiol. 36, 392-393

Seppenwoolde, J. H., Nijsen, J. F. W., Bartels, L. W., Zielhuis, S. W., van het Schip, A. D., Bakker, C. J. G. (2004). Magn. Reson. Med. 53, 76-84. doi: $10.1002 / \mathrm{mrm} .20320$

Van Es, R. J., Nijsen, J. F. W., van het Schip, A. D., Dullens, H. F., Slootweg, P. J., Koole, R. (2001). Int. J. Oral and Maxillofac. Surg. 30, 407-413. doi:10.1054/ijom.2001.0129
Vente, M. A., Hobbelink, M. G., van het Schip, A. D., Zonnenberg, B. A., Nijsen, J. F. (2007). Anticancer Agents Med. Chem. 7, 441459. doi: $10.2174 / 187152007781058569$

Vente, M. A., Nijsen, J. F., de Wit, T. C., Seppenwoolde, J. H., Krijger, G. C., Seevinck, P. R., Huisman, A., Zonnenberg, B. A., van den Ingh, T. S., van het Schip, A. D. (2008). Eur. J. Nucl. Med. Mol. Imaging 35, 1259-1271. doi:10.1007/s00259-0080747-8

X-5 Monte Carlo Team (2003). MCNP - a general monte carlo nparticle transport code, version 5. LA-UR-03-1987, LA-CP-030245, LA-CP-03-0284. Los Alamos, NM: National Laboratory

Yamaguchi, H., Waker, A. J., Radiat, J. (2007). Reseacrh (Tokyo) 48, 289-303

Zielhuis, S. W., Nijsen, J. F. W., de Roos, R., Krijger, G. C., van Rijk, P. P., Hennink, W. E., van het Schip, A. D. (2006a). Int. J. Pharm. 311, 69-74

Zielhuis, S. W., Nijsen, J. F. W., Krijger, G. C., van het Schip, A. D., Hennink, W. E. (2006b). Biomacromolecules 7, 2217-2223

Zielhuis, S. W., Nijsen, J. F., Dorland, L., Krijger, G. C., van het Schip, A. D., Hennink, W. E. (2006c). Int. J. Pharm. 6, 67-74

Zielhuis, S. W., Nijsen, J. F., Seppenwoolde, J. H., Bakker, C. J., Krijger, G. C., Dullens, H. F., Zonnenberg, B. A., van Rijk, P. P., Hennink, W. E., van het Schip, A. D. (2007). Biomaterials 28, 4591-4599 